\section{Adult vitelliform macular degeneration: clinicopathological study}

JJ Arnold', JP Sarks², MC Killingsworth³ ${ }^{3}$ EK Kettle ${ }^{2}$ and $\mathrm{SH}_{\text {Sarks }}^{2}$

\section{Introduction}

\begin{abstract}
Aims/background The yellow lesions of adult vitelliform macular degeneration (AVMD) slowly fade, progressing to hyperpigmentation or atrophy. This study aims to provide further observations on the location and nature of the vitelliform material. Methods This report describes the clinicopathological correlation of four eyes with AVMD. A retrospective histopathological study of a further 526 aged eyes previously graded for the stage of age-related macular degeneration (AMD) found another 10 eyes with similar pathology.
\end{abstract}

Results The predominant finding was a collection of extracellular material beneath the sensory retina at the fovea. This material was derived internally from photoreceptor outer segments and externally from the retinal pigment epithelium (RPE), the latter first undergoing hypertrophy and then disruption and attenuation. Fallout of foveal cones occurred over these lesions and the inner retina was thinned, which may explain macular hole formation in this condition. All affected eyes showed histopathological evidence of AMD.

Conclusions This study confirms that the vitelliform lesions of AVMD lie beneath the sensory retina. In contrast to previous reports, however, it is proposed that the lesions comprise mainly extracellular material consisting of photoreceptor debris, possibly the result of faulty phagocytosis by the RPE, mixed with pigment liberated as the RPE undergoes disruption. The vitelliform lesions therefore are a marker for the area of maximal RPE disturbance. Eye (2003) 17, 717-726. doi:10.1038/ sj.eye. 6700460

Keywords: adult vitelliform macular degeneration; adult foveomacular vitelliform dystrophy; age-related macular degeneration
The classical vitelliform macular lesion characterises Best's vitelliform dystrophy, but in adults similar lesions are less well categorised. In 1974, Gass ${ }^{1}$ described a 'peculiar foveomacular dystrophy' which he later termed 'foveomacular vitelliform dystrophy: adult type'. ${ }^{2}$ The hallmark of the condition is a yellow, slightly elevated lesion, one-third to one disc diameter in size, and often with pigment in the form of a spot, figure, or ring. At times the central pigment clump is the predominant feature, surrounded by a hypopigmented halo. As a result, many different terms have been applied to this picture, mostly emphasising the yellow vitelliform lesion, ${ }^{2-4}$ less commonly the pigment. ${ }^{5-7}$ A hereditary trait has been established in some cases but not in others, so that it has variously been termed a degeneration $^{8-10}$ or a dystrophy. ${ }^{2-5,11}$ In this report it is termed adult vitelliform macular degeneration (AVMD). The disease may present different phenotypes in the same family, ${ }^{12}$ or in the two eyes of the same individual, ${ }^{10,11}$ or even in the same eye at different times. ${ }^{10}$

Controversy exists as to the nature and site of the clinical lesion in AVMD. The yellow material gradually fades and in only one report ${ }^{7}$ has pathological examination been performed when it was still present, other reports being confined to eyes with pigment only, ${ }^{1}$ or after it has already progressed to an atrophic lesion. ${ }^{3}$ The site of the yellow material has therefore been placed either above the retinal pigment epithelium (RPE) ${ }^{7,10}$ or below the RPE., ${ }^{3,5}$ The most convincing correlation of this material has been by Dubovy et al, ${ }^{7}$ who showed that it corresponded to lipofuscin-laden cells in the subretinal space.

The aims of the present study are to report clinicopathological observations on the nature and location of subfoveal material in older eyes
${ }^{1}$ Marsden Eye Centre Sydney, Australia

${ }^{2}$ Prince of Wales Medical Research Institute and University of New South Wales

Sydney, Australia

${ }^{3}$ South Western Area Pathology Service Sydney, Australia

Correspondence: SH Sarks

15 Parnell Street Strathfield NSW 2135, Australia Tel: + 61297471433

Fax: +61297454640

E-mail: jssarks@

bigpond.net.au

Received: 5 April 2002 Accepted in revised form: 19 November 2002 
and to propose that it accounts for the clinical lesions of AVMD. The relationship of this material to AMD and to macular hole formation is described.

\section{Materials and methods}

Clinical definition of $A V M D$ We have used the generic term vitelliform lesion to denote a focal yellowish or yellowish pink slightly elevated lesion, often with a central pigment clump. The clinical spectrum includes a pigment clump surrounded by a depigmented halo. Alternatively, there may be a focal depigmented patch, sometimes surrounded by a ring of hyperpigmentation, which remains as the yellow material fades.

This report is based on the clinicopathological study of 530 postmortem eyes from 303 patients aged 43-97 years. All the patients had been examined clinically by one of us (SHS), the last examination ranging from 2 weeks to 60 months prior to death (mean 13.9 months). Examination included best-corrected visual acuity except where unobtainable, and direct fundoscopy. Fundus photography and fluorescein angiography were carried out where appropriate using the Zeiss $30^{\circ}$ fundus camera.

The eyes were obtained postmortem and either paraffin embedded for light microscopy (456 eyes) or fixed for electron microscopy (74 eyes) according to standard procedures. ${ }^{13}$ As previously described, ${ }^{14}$ the eyes had been divided into groups according to a basal laminar deposit as this reflected the stage of degeneration of the RPE (Table 1). Basal laminar deposit (BLD) was defined on light microscopy as a layer of extracellular material lying beneath the RPE and was of two types, termed early and late. Early BLD showed fine vertical striations and stained blue with picro-Mallory. Late BLD had a hyalinised structure and stained red with picro-Mallory. BLD was arbitrarily graded as thin or thick according to whether it was or was not taller than half the height of a normal RPE cell. ${ }^{15}$ The late component was always present when BLD became thick. Basal linear deposit, on the other hand, was seen only on electron microscopy as a layer of membranous debris external to the RPE basement membrane and is not described in this report.

Group I (no BLD, 146 eyes) was regarded as normal and Group II (patchy BLD, 223 eyes) as normal aging. AMD commenced in Group III (thin BLD, 69 eyes) in which $40 \%$ of the eyes showed a clinical pigment disturbance. Group IV (thick BLD, 92 eyes) had all shown clinical signs of AMD. Eyes with geographic atrophy (Group V) or clinically evident choroidal neovascularisation (Group VI) were excluded from this study. Drusen were described as hard or soft according to earlier histopathological descriptions. ${ }^{16}$

The study was performed in two stages. In the first, clinicopathological findings are described in four eyes from three patients (cases 1-3) diagnosed as AVMD during life. Observation of these patients commenced 1 year (case 1), 3 years (case 2), and 15 years (case 3 ) before death. No family histories were obtainable. The eyes of cases 1 and 2 were subsequently examined by light microscopy, the eyes of case 3 by electron microscopy. In the second part of this study, a retrospective search was made of the remaining 526 eyes in Groups I-IV to identify eyes with similar histopathological features. A further 10 eyes from seven patients were found, and the findings in these eyes are described.

\section{Results}

Case 1 A 74-year-old man suffering from chronic lymphatic leukaemia presented with a pink foveal lesion in each eye, about one-third disc diameter in size, with surrounding soft drusen (Figure 1). The lesions were associated with hyperpigmentation, which in the right eye formed an indistinct radiating pigment pattern. This pigment figure was overlain by faint yellow material. In the left eye, the lesion had a circumscribed border of hyperpigmentation but yellow material had not been noted. Vision was 6/12 vision in each eye. He died 18 months later.

Histopathological examination was possible only on the left eye. In the centre of the fovea the retina showed a marked loss of photoreceptors and small cystic spaces in

Table 1 Clinical findings and frequency of AVMD in 530 eyes

\begin{tabular}{|c|c|c|c|c|}
\hline & $\begin{array}{l}\text { Group I } \\
\text { No BLD }\end{array}$ & $\begin{array}{c}\text { Group II } \\
\text { Patchy BLD }\end{array}$ & $\begin{array}{l}\text { Group III Thin } \\
\text { Continuous } \\
\text { BLD }(\leq 7 \mathrm{~mm})\end{array}$ & $\begin{array}{c}\text { Group IV } \\
\text { Thick continous } \\
\text { BLD }(>7 \mathrm{~mm})\end{array}$ \\
\hline Number of eyes (persons) & $146(84)$ & $223(129)$ & $69(37)$ & $92(53)$ \\
\hline Mean age at death (years) & 61.7 & 73.8 & 78.7 & 82.3 \\
\hline $\begin{array}{l}\text { Eyes (\%) with clinically } \\
\text { evident pigment changes }\end{array}$ & $7(4.8 \%) \mathrm{a}$ & $7(5 \%) a$ & $28(40.1 \%)$ & $61(66.3 \%)$ \\
\hline
\end{tabular}

In Groups I and II, a solitary pigment spot was seen in a few eyes, sometimes located over a druse. 


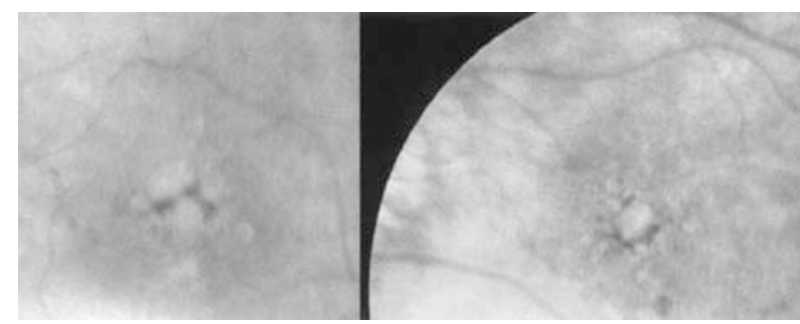

Figure 1 Case 1. Right and left eyes of a 74-year-old man with vitelliform lesions and surrounding soft drusen. In the right eye, this was associated with an indistinct radiating pigment pattern, and in the left eye, the lesion was surrounded by a hyperpigmented margin. Vision was $6 / 12$ in each eye.

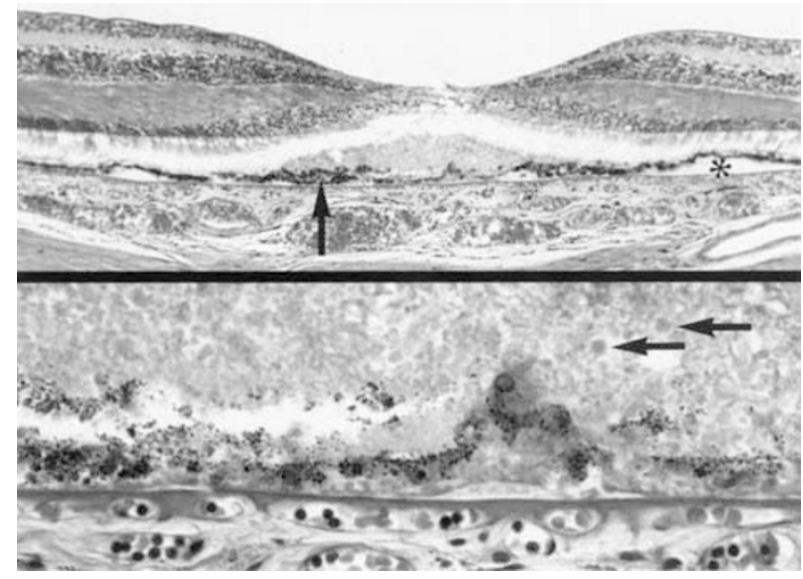

Figure 2 Case 1. Top: Section through left fovea, showing collection of subretinal debris. Overlying retina exhibits loss of photoreceptors and cystic degeneration. Beneath the centre of the fovea RPE is hypopigmented, and towards the edge RPE is hyperpigmented and reduplicated (arrow). Soft drusen (asterisk) have lost most of their contents. Picro-Mallory stain, $\times 160$. Lower: Higher magnification of subfoveal extracellular debris containing pale-staining rounded bodies (arrows) representing photoreceptor material. RPE shows disruption with the liberation of pigment granules. Basal deposits are evident beneath the RPE. Bruch's membrane is moderately thickened. Picro-Mallory stain, $\times 512$.

the inner layers. Beneath the retina was a mound of rounded bodies representing partly homogenised photoreceptor debris together with a small number of pigment granules (Figure 2).

The RPE was attenuated under the centre of the fovea and heaped up at the edge due to cells overriding each other, corresponding to the hyperpigmented margin. A continuous layer of BLD was present beneath the RPE and extended beyond the fovea, attesting that this eye had moderately advanced AMD and Bruch's membrane was thickened. Soft drusen were evident but most of their contents had been lost.

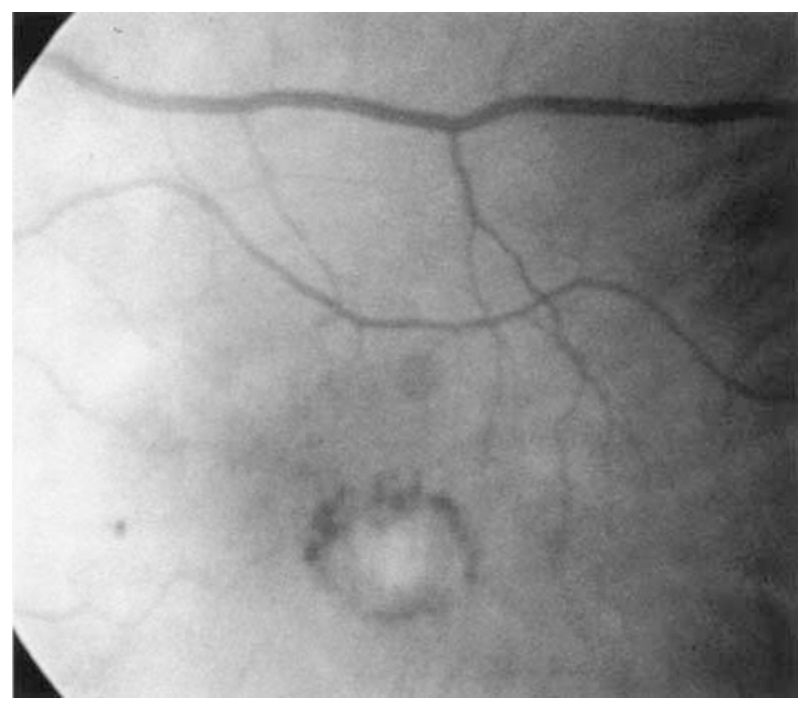

Figure 3 Case 2. Left eye of a 79-year-old man showing a circumscribed yellowish pink lesion about 0.5 disc diameters across, with a hyperpigmented border. There was minimal surrounding degeneration. The right eye had a similar circumscribed lesion within which atrophy was commencing. Vision was $3 / 60$ in the right eye, and $6 / 60$ in the left eye. The appearances were unchanged a year later and he died after a further 2 years.

Case 2 A 79-year-old man suffering from generalised vascular disease presented with $3 / 60$ vision in the right eye and 6/60 vision in the left eye. At each fovea there was a circumscribed pink area of hypopigmentation surrounded by a hyperpigmented border (Figure 3) measuring half a disc diameter across, while the surrounding retina appeared normal. In the left eye, a little yellow material was still present and the pigment appeared greyer, whereas in the right eye, there was commencing exposure of the choroidal vessels. When examined 1 year later there was minimal enlargement of the lesions and he died after a further 2 years.

In both eyes the histopathological abnormalities were localised to the fovea, but in the right eye the retina was partly displaced and this eye was excluded from the study. In the left eye, there was a mound of subretinal material (Figure 4). The RPE was disrupted and attenuated centrally and heaped up at the edge, similar to case 1. A thin layer of BLD was present. The subretinal debris consisted of photoreceptor debris containing rounded bodies, beneath which pigment was present within cell profiles showing varying degrees of disintegration and also as loose granules (Figure 5). Photoreceptor nuclei were reduced in number and only a few stunted cone inner segments projected beyond the external limiting membrane. The retina over the debris consequently was very attenuated. 


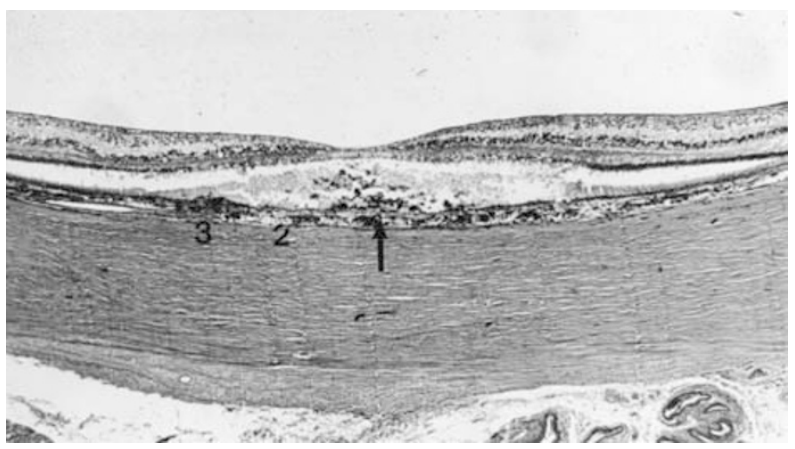

Figure 4 Section through left fovea showing mound of subfoveal material consisting of photoreceptor debris internally and pigment externally. RPE beneath the centre of the fovea shows disruption (arrow). This is surrounded by attenuation (2) and beyond this the RPE is hyperpigmented and heaped up (3). Outside the fovea the RPE appeared relatively normal. Note the retinal thinning at umbo due to loss of photoreceptors, which may explain predisposition to macular hole formation. PicroMallory stain, $\times 40$.

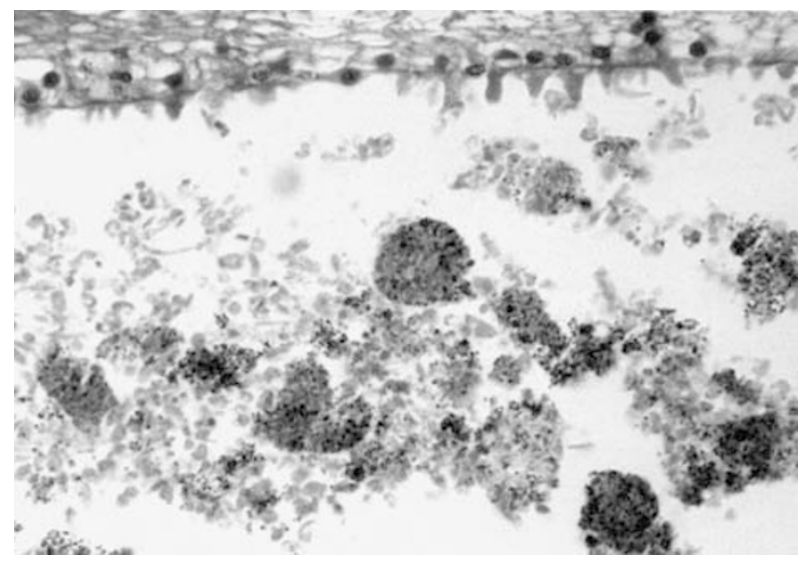

Figure 5 Higher magnification of subfoveal debris shown in Figure 4. It contains outer segment material, pigment-laden cell profiles, and loose pigment granules. Note that photoreceptors are reduced to stumps projecting beyond the external limiting membrane, which remains intact. Picro-Mallory stain, $\times 512$.

Case 3 A man suffering from alcoholic cirrhosis and peripheral vascular disease first presented at age 58 with a small focal pigment clump at each fovea, larger in the left eye. He was followed for 16 years, the pigment waxing and waning and in the left eye becoming associated with faint yellow material. This had faded before fluorescein angiography was performed at age 69, the angiogram demonstrating only hypofluorescence corresponding to the pigment surrounded by a hyperfluorescent halo. A patch of hypopigmentation developed but vision remained 6/9p. The right eye behaved similarly until a cataract precluded retinal assessment. He died aged 74 .
The morphologic findings in both eyes were similar. Figure 6 represents a section through the right fovea and shows a thick collection of outer segment material in the subretinal space. Pigment was sparse in this debris and was more conspicuous in a smaller parafoveal lesion. Outside the fovea small mounds of membranous debris lay on the apical surface of the RPE.

The smaller parafoveal lesion (Figure 7) is described in more detail as it better demonstrates the formation of subretinal debris from photoreceptors and the RPE. Here there was localised loss of inner and outer segments. Photoreceptor nuclei had largely disappeared, those photoreceptors remaining having stunted inner segments. The RPE was irregular, large hyperpigmented cells alternating with hypopigmented cells. A thin BLD was present and there was patchy loss of the choriocapillaris.

Figure 8 shows a vertical section through the parafoveal lesion. Here the inner segments were reduced in number; those remaining appeared stunted and contained tubules. The outer segments were distorted and convoluted, and became increasingly abnormal as they were traced towards the RPE. The bulk of the debris consisted of rounded or elongated bodies, the diameter of which approximated the diameter of the outer segments. These bodies appeared to be derived from the breakdown of outer segment discs (Figure 9) and contained tubules (Figure 10). The RPE was grossly abnormal and one cell appeared to be discharging its nonpigmented cytosol into the subretinal space, leaving a gap in which there were only a few pigment granules. Adjacent cells demonstrated bundling of pigment

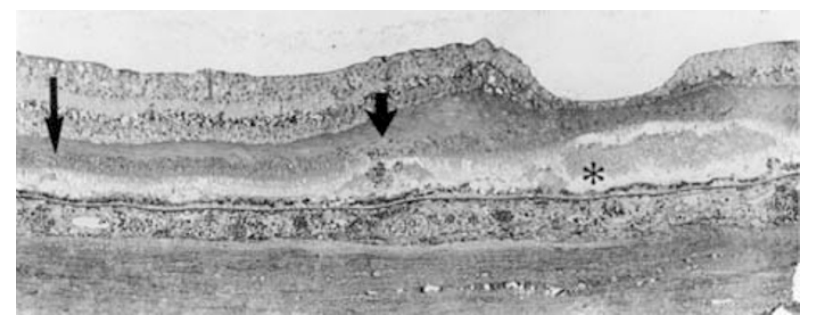

Figure 6 Case 3. Semithin section through the right fovea of a 74-year-old man. A clump of pigment and yellow material present in the seventh decade had faded to leave a patch of hypopigmentation when last seen a few months before death Vision remained 6/9 part. The section shows three areas of interest: (a) Beneath the foveal centre is a thick collection of outer segment material (asterisk) over which there is a pronounced loss of photoreceptors and their nuclei. The RPE here is irregular, with alternating hyperpigmented and hypopigmented cells. (b) Smaller parafoveal lesion (arrowhead, magnified in Figure 7) containing photoreceptor material and pigment and showing loss of overlying photoreceptor nuclei. (c) Mounds of apical debris (arrow, magnified in Figure 11). Methylene blue and basic fuchsin, $\times 72$. 


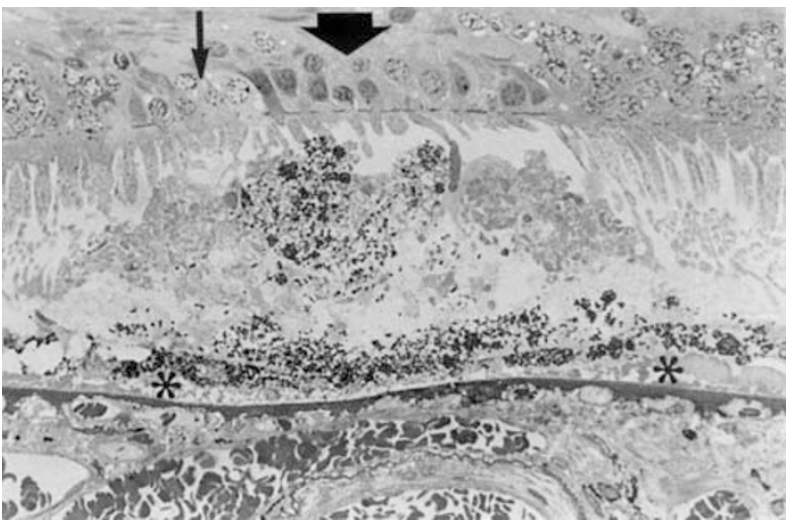

Figure 7 Higher magnification of the parafoveal area shown in Figure 6. Pigment granules and photoreceptor debris lie in subretinal space. Note the loss of overlying photoreceptor inner and outer segments and the loss of nuclei from the outer nuclear layer (arrowhead). Here the debris consists largely of pigment liberated from a disrupting RPE. The small arrow indicates the line of the vertical section through photoreceptor debris magnified in Figure 8. Basal laminar deposit is present (asterisks), but no basal linear deposit was found. Several choroidal capillaries are missing. Semithin section. Methylene blue and basic fuchsin $\times 512$.

granules. The late form of the BLD was present, but there was no membranous debris beneath the RPE basement membrane (basal linear deposit).

In the perifoveal region there were mounds of membranous debris on the apical surface of the RPE (Figure 11). Overlying these mounds the normally regular membrane stacks became increasingly disorganised and tended to lie horizontally and fuse together. The number of apical villi were reduced, suggesting that these apical mounds occurred at sites of faulty phagocytosis.

\section{Retrospective series}

Retrospective histopathological examination of the remaining 526 eyes in Groups I-IV found a further 10

Figure 8 Electron micrograph of the vertical section indicated in Figure 7, showing the subretinal debris, which internally appears derived from the photoreceptors and externally from the RPE. From above down note stunted inner segments (a), to which a few abnormal outer segments (b) remain attached. The innermost part of the subretinal debris (c) consists of a few distorted and convoluted outer segments. The bulk of the debris comprised rounded or oval bodies (d) (magnified in Figure 10). The RPE (e) is grossly abnormal and one necrotic cell appears to be discharging its nonpigmented cytosol into the subretinal space (arrow), leaving a gap in which there are only a few pigment granules. Adjacent cells demonstrate bundling of their pigment granules. The basal laminar deposit is present (asterisk), but there is no membranous debris beneath the RPE basement membrane (basal linear deposit). Bar marker $=20 \mu \mathrm{m}$. eyes of seven patients with similar extracellular subfoveal debris (Figure 12, Table 1). These eyes were found only in Groups III and IV, none being found in 369 eyes in Groups I and II. These additional patients had not

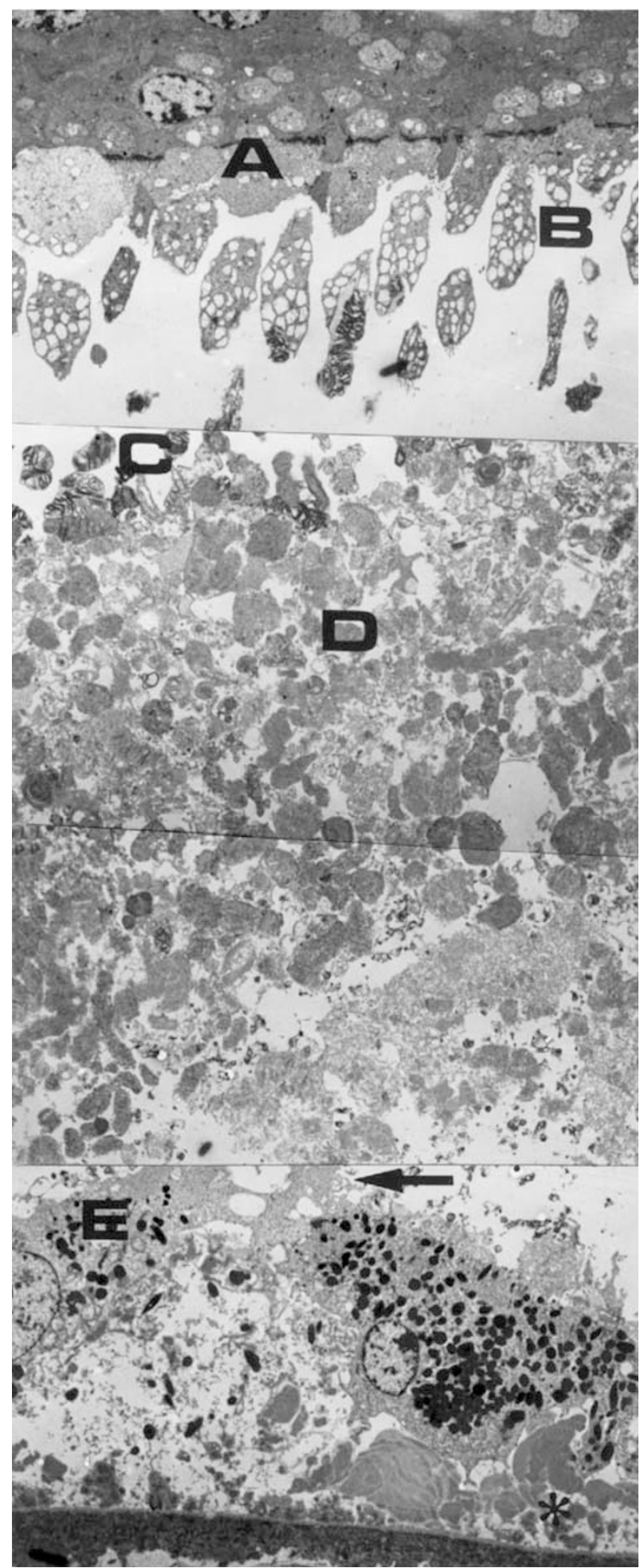




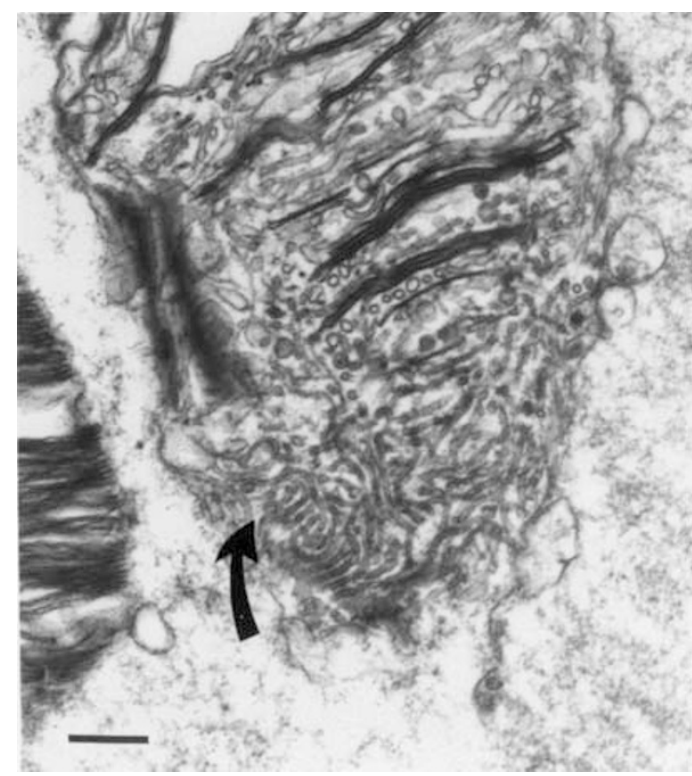

Figure 9 Electron micrograph showing the tip of the degenerating outer segment. Individual discs are breaking up to form randomly arranged tubules resembling fingerprints (curved arrow). Since there is apparent continuity between the discs and tubules, it is presumed that the tubules shown in Figure 10 are derived from outer segment discs. Bar marker $=0.5 \mu \mathrm{m}$.

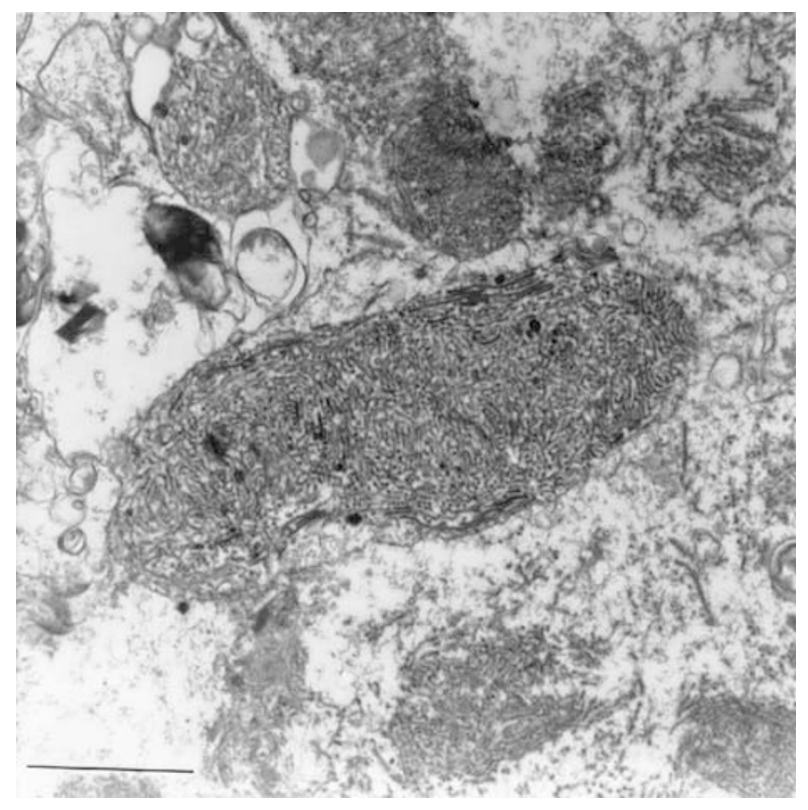

Figure 10 Higher magnification of bodies that form the bulk of the photoreceptor debris in Figure 8. These consist of densely packed tubules apparently resulting from the breakdown of outer segments as shown in Figure 9. Bar marker $=2 \mu \mathrm{m}$.

been diagnosed as AVMD clinically, but the diagnosis may have been missed. However, all had shown a pigment disturbance, described as a focal pigment clump

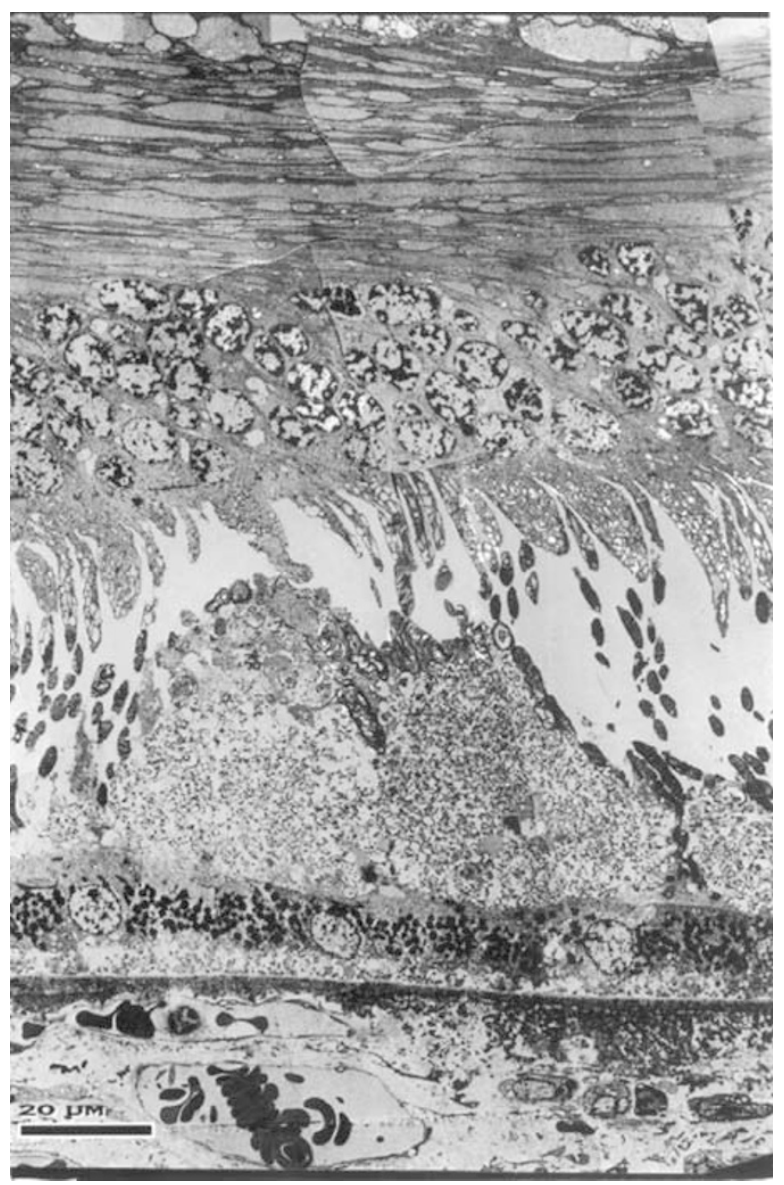

Figure 11 Electron micrograph of perifoveal area indicated in Figure 9 showing mounds of membranous debris lying on the apical surface of RPE. The remaining photoreceptor outer segments are moulded over this material, some orientated horizontally. The normally regular membrane stacks are disorganised and tend to fuse together. Note that apical villi of the RPE are absent. Bar marker $=20 \mu \mathrm{m}$.

in seven and more diffuse pigment changes in three. Table 2 summarises the features of all 14 eyes in this series.

The subretinal debris measured an average of $550 \mu \mathrm{m}$ in width (range $281-812 \mu \mathrm{m}$ ) and $95 \mu \mathrm{m}$ in depth (range $70-118 \mu \mathrm{m}$ ). It was located under the centre of the fovea in 11 eyes and up to $550 \mu \mathrm{m}$ from the centre in three eyes. One patient (case 3) had two lesions. The earliest change noted in the surrounding retina was shortening of the outer segments. When traced towards the centre of the lesion there was progressive fallout of photoreceptor nuclei, retinal pigment cells, and choroidal capillaries. The debris did not promote an inflammatory response, only an occasional macrophage in the choroid being found per section and these cells were not seen to be eroding Bruch's membrane.

In no case was the RPE in the macular region entirely normal, the least affected cells showing hyperpigmentation in situ and pigment bundling. At the 
margin of the lesions the cells were hypertrophic with curved apices which overlapped adjacent cells, at times forming a double layer. Centrally, the RPE showed

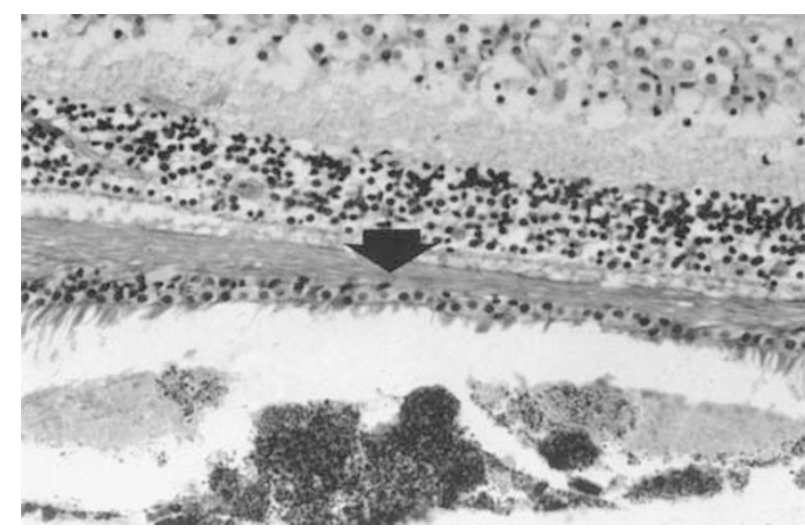

Figure 12 Eye 6 from retrospective series, AVMD not diagnosed during life but pathology similar to other cases. Section through pigment clump in the lateral part of fovea of an 88-yearold man. Hyperpigmented and enlarged RP cells show disruption, associated with photoreceptor debris. The overlying retina shows a marked loss of photoreceptors compared to more normal areas at sides. Note the loss of nuclei from the outer nuclear layer (arrowhead). Picro-Mallory stain, $\times 410$. distension and disruption with liberation of pigment into the subretinal space, both in membrane-bound bundles and as free granules, leaving the RPE as a moderately attenuated but nevertheless intact layer. There were no pigment-laden cells in the sub-RPE space. The subretinal extracellular debris was most developed and the photoreceptor fallout was most pronounced in the region of RPE disruption.

Although AVMD occurred only when AMD was present, it did not increase in frequency with the stage of degeneration, actually being found more frequently in Group III (10.1\%) than Group IV (7.6\%). Nor was it related to the number of soft drusen which were prominent in only two eyes.

Apical mounds of membranes were noted in four eyes and could be traced into the perifoveal region, but may be more common as they are difficult to recognise by light microscopy owing to the tendency for the retina to detach from the apical surface of the RPE.

\section{Possibility of postmortem artefact}

Liberation of pigment granules into the subretinal space and degeneration of outer segments can also result from

Table 2 Summary of findings in 14 eyes from 10 patients with subretinal extracellular debris (mean age 82.2 years)

\begin{tabular}{|c|c|c|c|c|c|c|}
\hline Eye no. & Case/eye & Age at death & $\begin{array}{l}\text { Interval (months) } \\
\text { from last } \\
\text { examination to death }\end{array}$ & Last VA & Fundus of study eye & Group \\
\hline 1 & $31 \mathrm{t}$ & 76 & 18 & $6 / 12$ & $\begin{array}{l}\text { See description of } \\
\text { lesion (Figure 1). Soft drusen }\end{array}$ & 4 \\
\hline 2 & $21 \mathrm{t}$ & 81 & 13 & $3 / 60$ & $\begin{array}{l}\text { See description of lesion } \\
\text { (Figure 3) }\end{array}$ & 3 \\
\hline 3 & $3 \mathrm{rt}$ & 74 & 7 & $6 / 60^{\mathrm{a}}$ & $\begin{array}{l}\text { Similar to left eye until } \\
\text { cataract obscured view }\end{array}$ & $3 \mathrm{EM}$ \\
\hline 4 & $31 \mathrm{t}$ & & 7 & $6 / 9$ & See description $(\mathrm{P})$ & $3 \mathrm{EM}$ \\
\hline 5 & $4 \mathrm{rt}$ & 81 & 12 & NA & $\begin{array}{l}\text { Yellow spot }+ \text { fine pigment } \\
\text { changes }(P)\end{array}$ & $3 \mathrm{EM}$ \\
\hline 6 & $5 \mathrm{rt}$ & 88 & 51 & $6 / 6$ & $\begin{array}{l}\text { Focal pigment clump with } \\
\text { depigmented halo } \\
\text { temporal to fixation }(\mathrm{P})\end{array}$ & 3 \\
\hline 7 & $51 \mathrm{lt}$ & & 51 & $6 / 9$ & $\begin{array}{l}\text { Pigment clump in lower temporal } \\
\text { fovea }(P)\end{array}$ & 3 \\
\hline 8 & $61 \mathrm{t}$ & 76 & 18 & $6 / 18$ & $\begin{array}{l}\text { Few small drusen and fine } \\
\text { pigment changes }\end{array}$ & 3 \\
\hline 9 & $7 \mathrm{rt}$ & 89 & 2 & NA & Focal pigment clump & 4 \\
\hline 10 & $8 \mathrm{rt}$ & 92 & 17 & $6 / 36^{\mathrm{a}}$ & Focal pigment clump & 4 \\
\hline 11 & $81 \mathrm{t}$ & & 17 & $6 / 18^{\mathrm{a}}$ & Focal pigment clump & 4 \\
\hline 12 & 9rt & 89 & 3 & NA & Focal pigment clump & 4 \\
\hline 13 & $91 \mathrm{t}$ & & 3 & NA & Focal pigment clump ${ }^{\mathrm{b}}$ & 4 \\
\hline 14 & $101 \mathrm{t}$ & 76 & 13 & $6 / 9$ & $\begin{array}{l}\text { Small soft drusen and fine } \\
\text { pigment }(P)\end{array}$ & 4 \\
\hline
\end{tabular}

NA: unobtainable due to poor cooperation;

aSignificant cataract present.

${ }^{b}$ Fundus obscured by cataract but similar to fellow eye on macroscopic examination.

P: fundus photography performed at some stage;

EM: examined by electron microscopy. 
postmortem autolysis, but the findings reported in this study are not considered to be artefact for the following reasons: (i) the focal nature of the pathology; (ii) the coexistence of the pigment granules and photoreceptor fallout within these lesions; (iii) the focal involvement of the overlying retina with reduction and deformation of the inner segments, loss of nuclei from the outer nuclear layer, and thinning of the foveolar retina predisposing to macular hole formation; and (iv) the demonstration on electron microscopy of a progressive increase in the severity of the photoreceptor damage as the debris is traced towards the RPE.

\section{Discussion}

This clinicopathological case series of 14 eyes with AVMD demonstrates that vitelliform lesions are located in the subretinal space and that the material has two sources. Internally, it is derived from the photoreceptor outer segment discs, a change accompanied by a loss of photoreceptor nuclei, and externally from the RPE, which first undergoes hypertrophy and then disruption. Lipofuscin accumulation is the most notable pathological event in Best's vitelliform dystrophy ${ }^{17,18}$ and it has been reported also in AVMD., ${ }^{3,7}$ The clinical spectrum of AVMD includes not only the typical yellowish lesions but also focal clumps of hyperpigmentation, ${ }^{4,10}$ and the yellow colour typical of AVMD may be apparent only when the subretinal material contains the requisite amount of loose lipofuscin and photoreceptor debris.

The subretinal location of the vitelliform material is supported by clinical observations. AVMD shows certain similarities to the entity described by Gass ${ }^{19}$ as vitelliform macular detachments associated with basal laminar drusen, in which biomicroscopy clearly points to the yellow material lying anterior to the RPE. During the vitelliform stage of this condition, a change in colour and clarity of the RPE is observed: where the yellow material overlies the pigment, the pigment appears grey and blurred, whereas when the yellow material retracts, the RPE is unmasked and appears black and distinct. In AVMD, the lesions are generally smaller but the pigment can display similar changes in appearance. ${ }^{10}$ This cycle observed clinically strongly suggests that in AVMD the yellow material likewise forms a screen anterior to the RPE. Ultimately, in both conditions an area of geographic atrophy develops that corresponds to the size of the yellow lesion, implying the material is an indicator of advanced damage to the RPE.

Since the yellow material fades in time, most previous reports have been confined to eyes with hyperpigmentation only, ${ }^{1}$ or after the eye has already progressed to an atrophic lesion. ${ }^{3}$ These reports drew attention to material beneath the RPE, although Gass ${ }^{1}$ also described pigment-laden cells under the retina. Jaffe and Schatz ${ }^{6}$ reported the eye of an 80-year-old man with a pigment clump surrounded by a yellowish halo that was believed to correspond to PAS + ve material beneath an attenuated RPE. This material, however, resembles the late amorphous form of the BLD, which could not account for the yellow lesion since it persists in AMD after atrophy has ensued. ${ }^{14}$

Dubovy $e t a l^{7}$ have provided the most convincing pathological confirmation of the subretinal location of the material, demonstrating large round pigment-laden cells in the subretinal space. This location is confirmed in the present study, but the vitelliform lesion is attributed also to extracellular material comprising photoreceptor debris, pigment granules, and RPE cells in varying stages of disintegration. Jaffe and Schat $z^{6}$ had noted that the sensory retina was detached by an eosinophilic fluid and that photoreceptors were absent at the fovea, so it is possible that the subretinal fluid they described also contained photoreceptor elements. Dubovy et $a l^{7}$ also described debris in the subretinal space in their case 2. In the present report, pigment-laden cells had migrated into the retina only rarely, the difference from the cases described by Dubovy et $a l^{7}$ being that the RPE showed disruption rather than distension as presumably the cells had broken down before the external limiting membrane was breached.

In contrast to AMD in which histopathological abnormalities commence as basal laminar deposits beneath the RPE, in AVMD the earliest changes involved the photoreceptors. In the retina around the lesions, there was shortening and distortion of the photoreceptor outer segments. Then as the photoreceptors were traced towards the centre of the lesion they became progressively abnormal with fallout of nuclei. The inner segments, the site where outer segment disc protein is normally produced, became stunted and contained tubules. The outer segments were also abnormal and on light microscopy appeared as a collection of rounded bodies which electron microscopy showed also to consist of tubules. Continuity could be demonstrated between the breakdown of outer segment discs and the formation of the tubules.

Focal loss of photoreceptors was a prominent feature of the cases in this report, agreeing with other descriptions ${ }^{1,3,6,7}$ that have noted focal loss of photoreceptor nuclei with loss of inner and outer segments overlying the lesion. In our cases 1 and 2, the outer nuclear layer was very attenuated with cystic changes and this may explain the predisposition to macular hole formation, which has been reported in both $\mathrm{AVMD}^{20}$ and Best's vitelliform dystrophy. ${ }^{21,22}$ 
Some RPE cells appear to lose their microvilli as demonstrated in case 3 , and Patrinely et $a l^{3}$ also noted that the microvilli become 'stubby'. Possibly as a consequence, scattered mounds of membranous debris were found on the apical surface of the RPE around the lesion, and the outer segments overlying these apical mounds were abnormal and misaligned. The mounds appear to represent a focal area of faulty phagocytosis by the RPE, but they are not specific for AVMD as similar mounds are observed also in AMD. ${ }^{23}$ At the same time, the RPE undergoes hypertrophy, the cells coming to override one another around the margin of the lesion to form two layers. At the centre of the lesions, some RPE cells were disrupted, but in all the eyes in our series and in previous reports, the RPE remained an intact layer apart from one eye described by Dubovy et $a l^{7}$ in which there was a small $(0.3 \mathrm{~mm})$ discontinuity filled with fibroglial tissue.

All eyes in our series showed evidence of AMD as previously defined in histopathologic studies by the presence of a continuous layer of BLD under the fovea. ${ }^{14}$ However, this also reflected the advanced age of the patients at death and AVMD did not become more prevalent as AMD increased in severity, being no more frequent in Group IV than in Group III. There is therefore no direct relationship to AMD and the evolution of AVMD is also slower than AMD, with a consequently better prognosis. Moreover, unlike AMD, the choroid developed a negligible macrophage response to the vitelliform material, possibly because the subretinal space is protected from inflammation by immune privilege. $^{24}$

In conclusion, this study supports an earlier clinical report $^{10}$ that placed the vitelliform material anterior to the RPE; it therefore confirms the clinicopathological study of Dubovy et $a l^{7}$ which clearly demonstrated the subretinal location, although in the present report the vitelliform lesion is attributed also to extracellular debris. It is suggested that defective phagocytosis leads to an accumulation of outer segment debris in the subretinal space and this becomes admixed with debris derived from RPE cell disruption. The accumulation of this debris may be dependent on a slower rate of RPE fallout, and the fact that vitelliform material is not seen in most cases of AMD may be because the RPE and photoreceptors mostly disappear before the debris has had time to build up.

\section{Acknowledgements}

We thank the Department of Medical Illustration, Prince of Wales Hospital, Sydney, for assistance in preparation of the photographs.

\section{References}

1 Gass JDM. A clinicopathologic study of a peculiar foveomacular dystrophy. Trans Am Ophthalmol Soc 1974; 72: 139-156.

2 Gass JDM. Stereoscopic Atlas of Macular Diseases: Diagnosis and Treatment, 2nd edn. Mosby-Year Book, Inc: St Louis, 1977, p 170.

3 Patrinely JR, Lewis RA, Font RL. Foveomacular vitelliform dystrophy, adult type. A clinicopathologic study including electron microscopic observations. Ophthalmology 1985; 92: 1712-1718.

4 Burgess DB, Olk RJ, Uniat LM. Macular disease resembling adult foveomacular vitelliform dystrophy in older adults. Ophthalmology 1987; 94: 362-366.

5 Vine AK, Schatz H. Adult onset foveomacular pigment epithelial dystrophy. Am J Ophthalmol 1980; 89: 680.

6 Jaffe GJ, Schatz H. Histopathologic features of adult-onset foveomacular pigment epithelial dystrophy. Arch Ophthalmol 1988; 106: 958-960.

7 Dubovy SR, Hairston RJ, Schatz H, Schachat AP, Bressler NM, Finkelstein D et al. Adult-onset foveomacular pigment epithelial dystrophy. Clinicopathologic correlation of three cases. Retina 2000; 20: 638-649.

8 Epstein GA, Rabb MF. Adult vitelliform macular degeneration: diagnosis and natural history. $\mathrm{Br} J$ Ophthalmol 1980; 64: 733

9 Bloom LH, Swanson DE, Bird AC. Adult vitelliform macular degeneration. Br J Ophthalmol 1981; 65: 800.

10 Greaves AH, Sarks JP, Sarks SH. Adult vitelliform macular degeneration: a clinical spectrum. Aust NZ J Ophthalmol 1990; 18(2):171-178.

11 Gutman T, Walsh JB, Henkind P. Vitelliform macular dystrophy and butterfly-shaped epithelial dystrophy: a continuum? Br J Ophthalmol 1982; 66: 170-173.

12 Bernasconi OR, Piguet B. Pattern dystrophies and intrafamilial phenotypic variation. Klin Monatsbl Augenheilkd 1996; 208(5): 291-293.

13 Sarks SH, van Driel D, Maxwell L, Killingsworth M. Softening of drusen and subretinal neovascularization. Trans Ophthalmol Soc UK 1980; 100: 414-422.

14 Sarks SH. Ageing and degeneration in the macular region: a clinico-pathological study. Br J Ophthalmol 1976; 60: 324-341.

15 van der Schaft TL, Mooy CM, de Bruijn WC, Oron FG, Mulder PGH, de Jong PTVM. Histologic features of the early stages of age-related macular degeneration. A statistical analysis. Ophthalmology 1992; 99: 278-286.

16 Sarks SH. Drusen and their relationship to senile macular degeneration. Aust J Ophthalmol 1980; 8: 117-130.

17 Weingeist TA, Kobrin JL, Watzke RC. Histopathology of Best's macular dystrophy. Arch Ophthalmol 1982; 100: 1108-1114.

18 O'Gorman S, Flaherty WA, Fishman GA, Berson EL. Histopathologic findings in Best's vitelliform macular dystrophy. Arch Ophthalmol 1988; 106: 1261-1268.

19 Gass JDM, Jallow S, Davis B. Adult vitelliform macular detachment occurring in patients with basal laminar drusen. Am J Ophthalmol 1985; 99: 445-459.

20 Noble KG, Chang S. Adult vitelliform macular degeneration progressing to full-thickness macular hole. Arch Ophthalmol 1991; 109: 325. 
21 Glacet-Bernard A, Coscas G. Full-thickness macular hole and retinal detachment complicating Best's disease. Eur J Ophthalmol 1993; 3(1): 53-54.

22 Schachat AP, de la Cruz Z, Green WR, Patz A. Macular hole and retinal detachment in Best's disease. Retina 1985; 5(1): $22-25$.
23 Sarks JP, Sarks SH, Killingsworth MC. Evolution of geographic atrophy of the retinal pigment epithelium. Eye 1988; 2: 552-577.

24 Streilein JW, Ksander BR, Taylor AW. Immune deviation in relation to ocular immune privilege. J Immunol 1997; 158(8): $3557-3560$ 